\title{
Factor VIII related antigen in the assessment of vasculitis
}

\author{
A D WOOLF, ${ }^{1}$ G WAKERLEY, ${ }^{1}$ T B WALLINGTON ${ }^{2}$ D G I SCOTT, ${ }^{3}$ AND \\ P A DIEPPE ${ }^{\prime}$
}

From the ${ }^{1}$ Departments of Medicine and Haematology, Bristol Royal Infirmary; the ${ }^{2}$ South Western Regional Transfusion Centre, Bristol; and the ${ }^{3}$ Department of Rheumatology, University of Birmingham

SUMMARY Factor VIII related antigen, an endothelial cell product, was markedly raised in systemic necrotising arteritis, reflecting disease activity, but was not raised in active cutaneous vasculitis. In rheumatoid arthritis high levels were only found in systemic vasculitis or Felty's syndrome, but in other connective tissue diseases increased levels were more frequently detected and usually related to disease activity. It did not correlate with $\mathrm{C}$ reactive protein. It was also raised in non-inflammatory peripheral vascular disease and after surgery and was not specific for vasculitic endothelial damage. Factor VIII related antigen may be useful in identifying and monitoring systemic necrotising and large vessel arteritis.

Key words: von Willebrand's factor, C reactive protein, endothelium, arteritis, Wegener's granulomatosis, periarteritis nodosa, connective tissue diseases, rheumatoid arthritis, ischaemia.

Vasculitis may arise de novo or as a feature of various connective tissue diseases, ${ }^{1}$ its consequences depending on the size, site, and number of blood vessels affected. ${ }^{2}$ Diagnosis is difficult and may require invasive investigation. Small vessel vasculitis rarely causes serious internal organ dysfunction, in contrast with the aneurysmal or occlusive lesions of small and medium muscular arteritis. ${ }^{1-6}$ There is no laboratory investigation that distinguishes between these, nor that consistently reflects disease activity. $^{26}$

Factor VIII related antigen (FVIII RAg) has been proposed as a marker of vascular damage. ${ }^{7}$ It is a high molecular weight glycoprotein,${ }^{8}$ with a half life of 240-270 min, ${ }^{910}$ present in ${ }^{11-13}$ and synthesised by ${ }^{14-16}$ endothelial cells. Raised circulating levels have been demonstrated after experimental vascular injury $^{7}$ and in a variety of clinical conditions, ${ }^{17-31}$ often in association with overt vascular disease. ${ }^{25} 2931$ Its usefulness in clinical practice in the assessment of vasculitis has not, however, been established.

We have therefore studied the sensitivity and specificity of changes in the plasma FVIII RAg concentration in detecting the presence of systemic vasculitis and monitoring its treatment.

Accepted for publication 24 November 1986.

Correspondence to $\operatorname{Dr}$ A D Woolf, Department of Medicine. Bristol Royal Infirmary, Bristol BS2 $8 \mathrm{HW}$.

\section{Patients and methods}

\section{PATIENTS}

Two hundred and eighty eight patients were included in the study- 51 patients with different types of vasculitis, 99 normal, and 138 disease controls. Most patients were studied prospectively, some were studied serially.

\section{Vasculitis}

Patients were subdivided into three different groups depending on the size of the largest blood vessel involved.

Small vessel vasculitis. This group $(\mathrm{n}=15)$ of patients had either clinical or histological evidence of vasculitis restricted to small blood vessels such as arterioles, capillaries, and venules. Clinical features included non-thrombocytopenic purpura, maculopapular skin rashes, minor nail edge or nail fold lesions. Clinical diagnoses included SchönleinHenoch purpura $(n=3)$, cutaneous vasculitis $(n=7)$, and rheumatoid vasculitis $(n=5)$. In 13 patients vasculitis appeared to be restricted to the skin, but two patients with Schönlein-Henoch purpura had systemic disease with renal involvement.

Systemic necrotising arteritis. These patients $(n=34)$ had clinical or histological evidence of vasculitis involving small or medium sized arteries. Clinical 
features of arteritis included mononeuritis multiplex, peripheral gangrene, and deep cutaneous ulcers. Histology confirmed an arteritis in 26 patients. In eight patients this histological confirmation of vasculitis was restricted to renal biopsies, which showed microscopic polyarteritis (focal segmental necrotising glomerulonephritis) but negative glomerular immunofluorescence. These patients had clinical polyarteritis nodosa. Clinical diagnoses in the whole group were Wegener's granulomatosis $(n=11)$, polyarteritis nodosa $(n=13)$, and arteritis complicating rheumatoid disease $(n=10)$.

Large vessel arteritis. Two patients had a diagnosis of Takayasu's arteritis confirmed by angiography $(n=1)$ and angiography plus histology $(n=1)$. Both had moderate or severe stenotic changes on angiography affecting many arteries, including the carotid arteries, the aortic arch, and subclavian arteries. One patient had evidence of active systemic disease with a marked acute phase response, whereas the other patient had no systemic symptoms, normal acute phase proteins, and was presumed to be in the 'pulseless' phase of his disease.

\section{Normal controls}

These comprised healthy blood donors $(n=75)$ and patients with osteoarthritis $(n=24)$ but without any inflammatory or vascular disease.

\section{Disease controls}

As vasculitis may accompany many connective tissue diseases, including systemic lupus erythematosus, rheumatoid arthritis, and polymyositis, it was important to examine patients with these diseases in the absence of clinical or histological evidence of vasculitis to compare and contrast them with patients with active vasculitis. In addition, we also examined patients with non-inflammatory vascular diseases (Raynaud's disease-23 patients, peripheral vascular disease without rest pain-24 patients) and patients with vascular damage directly attributable to operative trauma (arthroplasty for osteoarthritis-five patients).

Rheumatoid arthritis. These patients $(\mathrm{n}=51)$ fulfilled the criteria of the American Rheumatism Association for definite or classical rheumatoid arthritis ${ }^{32}$ and had no clinical or histological evidence of vasculitis. They could be subdivided further into patients with active arthritis but no extra-articular manifestations $(n=29)$, arthritis complicated by typical subcutaneous rheumatoid nodules $(n=15)$, and seven with Felty's syndrome.

Connective tissue diseases. These included patients with systemic lupus erythematosus $(n=13)$, mixed connective tissue disease $(n=7)$, polymyositi $(n=4)$, and scleroderma $(n=11)$. Patients were divided into active or inactive disease on clinicap criteria.

\section{METHODS}

\section{Clinical assessment}

In cross sectional studies patients were examined a time when their vasculitis was considered mos active. This was based on clinical features such as. new arteritic or vasculitic lesions, recent neurow pathy, or active systemic illness. In some patien\& there was confirmation of active systemic disease b. laboratory assessments such as urine microscop 9 and measurements of haemoglobin, white ceP count, erythrocyte sedimentation rate (ESR), and reactive protein by radial immunodiffusion. ${ }^{33}$

\section{FVIII related antigen assay}

Circulating factor VIII related antigen was assaye by an enzyme linked immunosorbent assay ${ }^{34}$ using commercially available antisera. The test was pefo formed in microtitre plates. The first layer was rabbit antihuman FVIII RAg (DAKO), followed by diluted sample or standard, and the third layer wa rabbit antihuman FVIII RAg conjugated wit horseradish peroxidase (DAKO), which was thef developed with $O$-phenylenediamine and hydrogef peroxide and read at $430 \mathrm{~nm}$. Results were ex pressed as a percentage of a normal control. Th normal range was defined as within two standar deviations of the mean level detected in healt blood donor controls. The coefficient of variation between batches was $5 \%$.

\section{STATISTICAL ANALYSIS}

The Mann-Whitney $U$ test was used to look fơ significant differences, comparing healthy blood donors with the patient groups unless stated otheb wise. The paired $t$ test was used in the comparison of serial data.

\section{Results}

CROSS SECTIONAL DATA

There was no significant difference between health blood donors and the older osteoarthritic controts (mean (SD) $103(59) \%$ ).

\section{Vasculitis (Fig. 1)}

FVIII related antigen was raised in 32 of 34 patien with active systemic necrotising arteritis (mean (SLB) $311.3(137 \cdot 1) \%, p<0.001)$, independent of the underlying clinical disease. Only two patients with microscopic polyarteritis had normal levels of FVIमू 


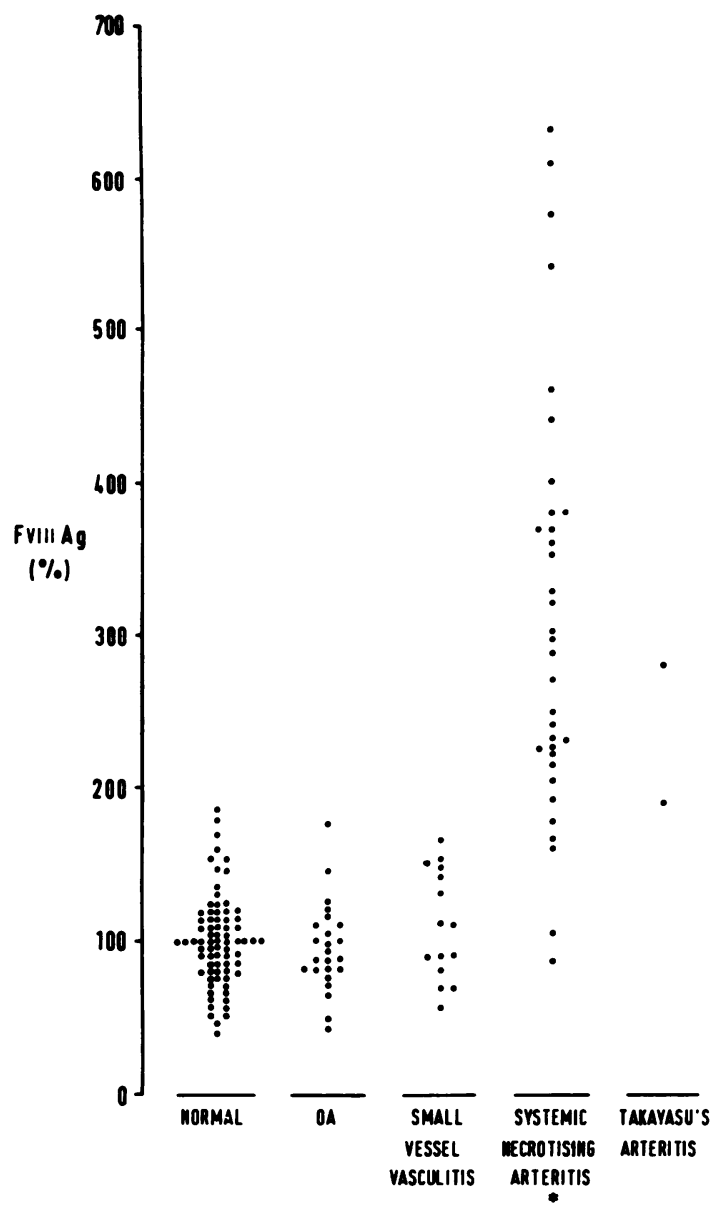

Fig. 1 Factor VIII RAg levels in patients with vasculitis and in controls. ${ }^{*} p<0.001$.

RAg: one had relatively minor systemic symptoms, but the other had classical multisystem disease with skin, joint, and lung symptoms as well as renal involvement. In contrast, FVIII related antigen levels were normal in all patients with small vessel vasculitis (mean (SD) $110.3(35.7) \%$, NS). These results were repeatable and remained within the normal range in serial studies in a number of patients. FVIII RAg levels were also normal in the two patients with Schönlein-Henoch purpura with systemic involvement (renal disease). In the two patients with large vessel vasculitis (Takayasu's arteritis) increased levels of FVIII $\mathrm{RAg}$ were detected $(189 \%, 280 \%)$.

Disease controls (Fig. 2)

Rheumatoid arthritis. FVIII RAg was not raised in patients with rheumatoid arthritis without distinct extra-articular features, though most had active synovitis (mean (SD) $112 \cdot 1(35 \cdot 1) \%$, NS). Two of the three patients with raised levels $(184 \%, 198 \%)$ had marked weight loss and acute phase responses but little synovitis and no other definable extraarticular features. FVIII RAg was not raised in patients with rheumatoid nodules $(124.9$ (36.6)\%, NS), but was increased in Felty's syndrome in the absence of clinical vasculitis (435.7 (54.9)\%, $\mathrm{p}<0.005)$.

Connective tissue diseases. FVIII RAg was significantly increased in patients with systemic lupus erythematosus (SLE), mixed connective tissue disease (MCTD), and polymyositis (192.9 $(134.5) \%, p<0.001)$, but this was variable, often reflecting clinical disease activity (Fig. 2). It was not significantly raised in progressive systemic sclerosis

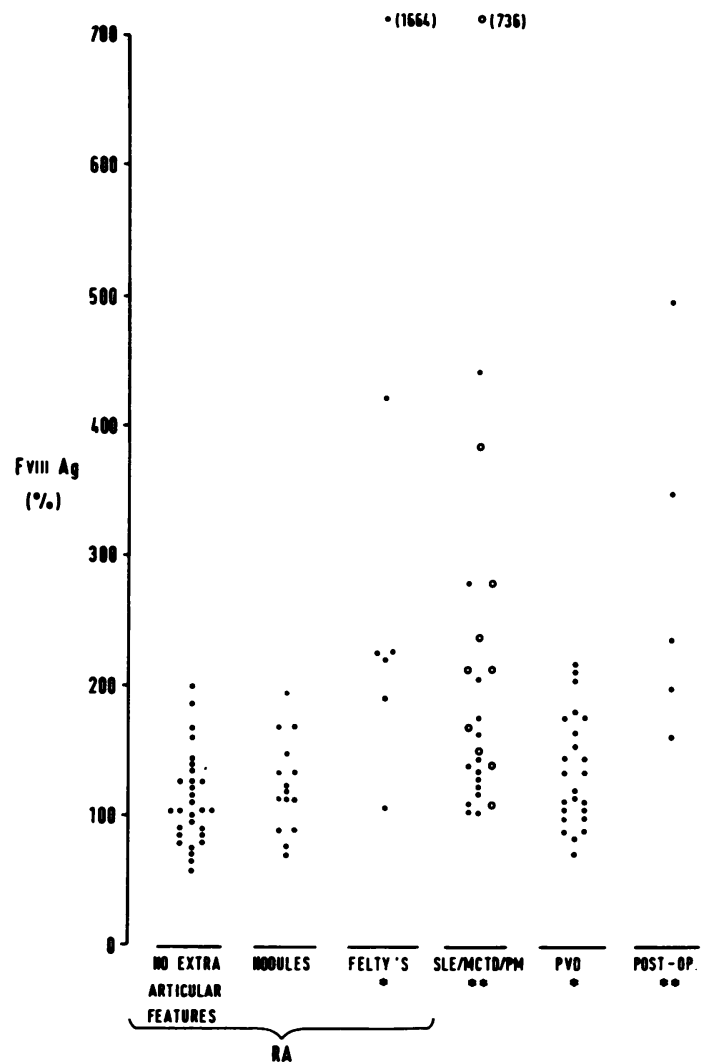

Fig. 2 FactorVIIIRAglevels in rheumatoid arthritis $(R A)$, connective tissue diseases (systemic lupus erythematosus (SLE), mixed connective tissue disease (MCTD), and polymyositis $(P M))$, peripheral vascular disease $(P V D)$, and postoperative patients. Patients with active connective tissue disease on clinical criteria are represented byo. ${ }^{*} p<0.005 ;{ }^{* *} p<0.001$. 
$(141.7(73.5) \%$, NS), apart from one patient with an ischaemic finger $(322 \%)$. These patients, however, were longstanding cases with clinically inactive disease.

Primary Raynaud's disease. FVIII RAg was not raised in primary Raynaud's disease $(100 \cdot 4(36.5) \%$, NS). It was, however, slightly but significantly raised in intermittent claudication in the apparent absence of irreversible ischaemia (134.5 (41.7)\%, $\mathrm{p}<0.005$ ).

Arthroplasty. FVIII RAg was significantly increased $48 \mathrm{~h}$ after arthroplasty for osteoarthritis (288.8 $(134.8) \%, p<0 \cdot 001)$.

\section{LONGITUDINAL DATA}

Seven patients with systemic vasculitis were studied longitudinally (three with Wegener's granulomatosis, four with polyarteritis nodosa) (Fig. 3). At presentation, all had raised FVIII RAg levels (390 $(135) \%)$. Five of the patients showed a good clinical response to treatment and there was a concomitant

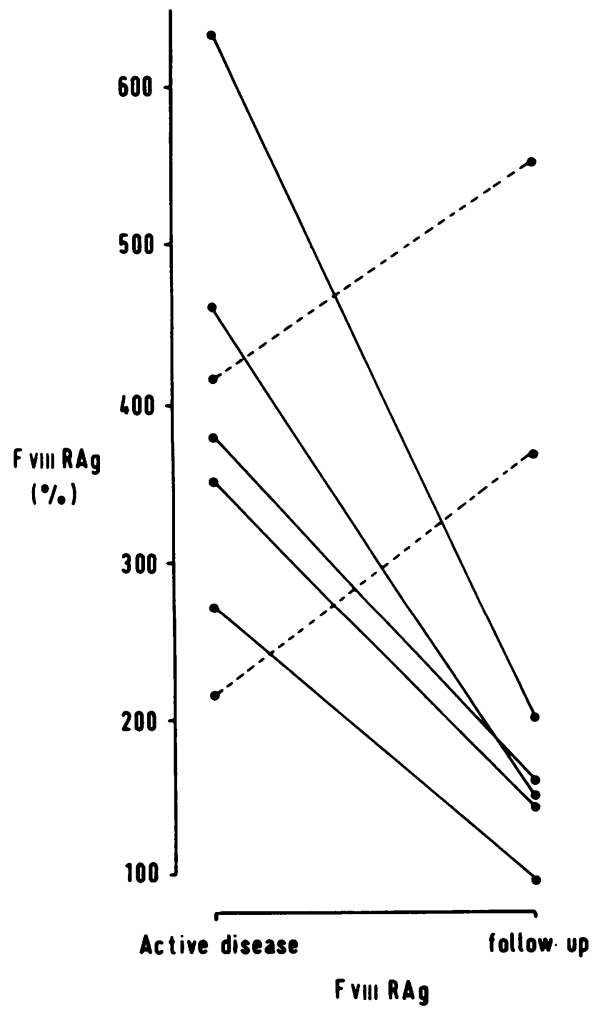

significant fall in factor VIII RAg to 148 (27) \% $(\mathrm{p}<0 \cdot 001)$, to within the normal range in four case Two cases, however, showed no response therapy: one dying from septicaemia complicationg immunosuppression, and the other dying from perforation of the bowel. These patients showed fall in FVIII RAg during therapy before their final fatal episode.

A direct comparison of FVIII RAg with is reactive protein (CRP) shows that the latter was:a poor indicator of disease activity in these patients. was sometimes normal at presentation, and chang\&s did not reflect the clinical response to treatmerg, remaining either raised or normal throughout in six of the seven patients (Fig. 3).

A patient with polyarteritis nodosa was studied closely over nine months (Fig. 4). Changes in FVH RAg appeared to mirror clinical disease activit Raised levels were detected shortly after presenta tion, which fell with response to treatment, rose jwst before clinical deterioration, and were unaffected an episode of intercurrent infection which provoked an acute phase response. Changes in FVIII R

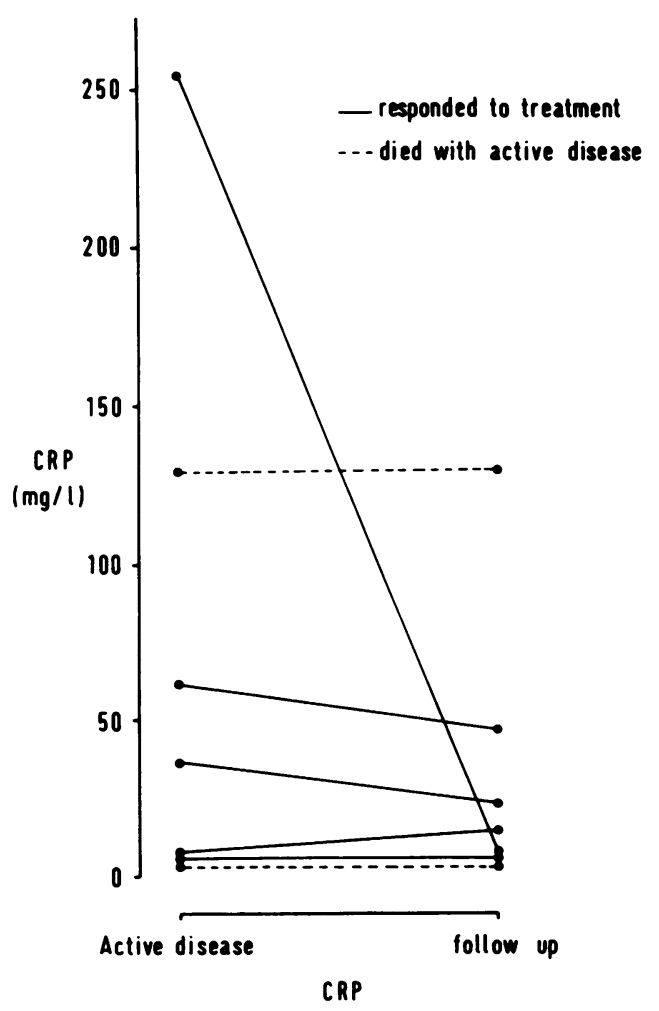

Fig. 3 Factor VIII RAg and C reactive protein (CRP) levels in patients with systemic necrotising arteritis at presentation and follow up. 

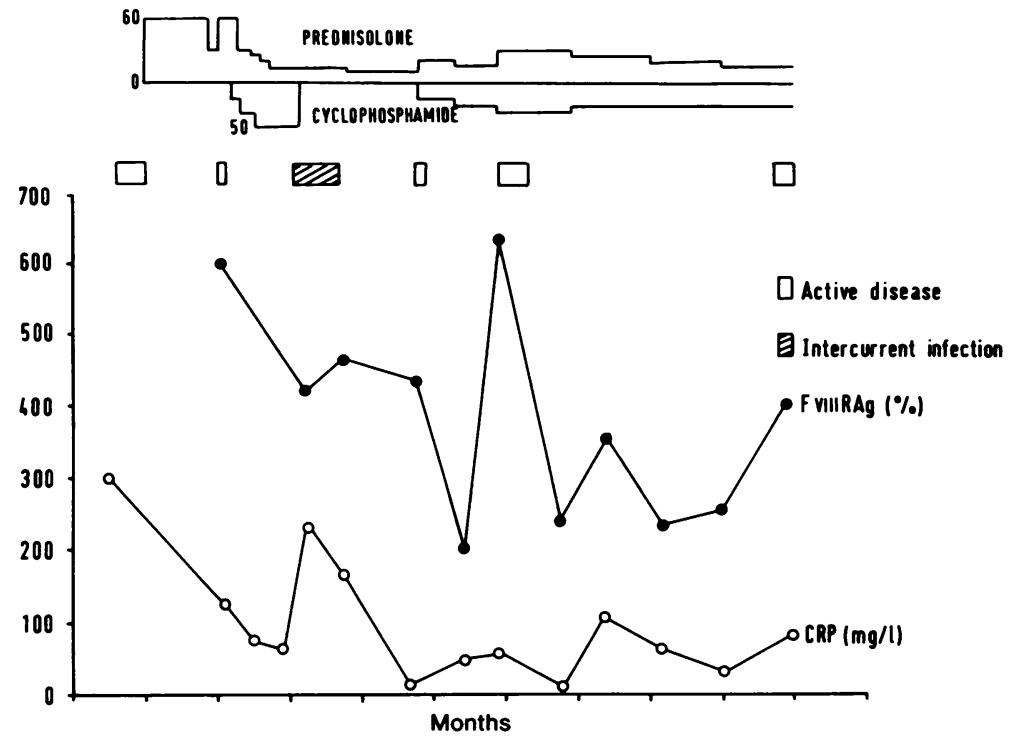

Fig. 4 A patient with polyarteritis nodosa followed up over nine months, with frequent assessments of FVIII RAg, CRP, and clinical disease activity.

were more marked than changes in CRP and appeared to be more specific for variation in disease activity.

FACTOR VIII RAg AND CRP

There was no correlation between CRP and factor VIII RAg in all patients studied with rheumatoid arthritis $(r=0.080)$, nor in systemic necrotising arteritis $(r=0.035)$. There were often markedly discordant results. In one patient with Takayasu's arteritis an increase of FVIII RAg was the only laboratory abnormality detected, ESR and CRP being normal.

\section{Discussion}

Factor VIII RAg is present in ${ }^{11-13}$ and synthesised by ${ }^{14-16}$ endothelial cells. It is also present in platelets $^{35} 36$ and synthesised by megakaryocytes. ${ }^{37}$ It is associated with platelet adhesion to the subendothelium..$^{38}$ It has been proposed as a marker of endothelial cell injury ${ }^{70}{ }^{31}$ and is raised in a variety of diseases, ${ }^{17-31}$ often complicated by vascular damage, but its use in clinical practice has not been established.

We have found markedly increased FVIII RAg levels in patients with active systemic necrotising arteritis and large vessels arteritis, in contrast with those with active small vessel vasculitis, even when complicated by renal impairment, and this is supported by other recent reports ${ }^{3139}{ }^{40}$ The prognosis of vasculitis is related to the size of vessels involved $^{6}$ : it is worse with necrotising systemic arteritis, which leads to either aneurysm formation and haemorrhage or to occlusion and distal infarction. The size of vessel involved may, however, only be determined by investigations such as biopsy or angiography with their subsequent morbidity as there are no discriminating laboratory tests available at present. This distinction between small vessel vasculitis and systemic necrotising arteritis by FVIII RAg level may therefore prove of great value in identifying those cases which require these invasive investigations.

Serial data suggest that FVIII RAg levels reflect disease activity in systemic necrotising arteritis and were more useful than $C$ reactive protein. On occasion a rise in FVIII RAg was noted before a clinically apparent flare in disease activity. Persistent increase was associated with a poor prognosis. This may allow more effective monitoring of response to immunosuppressive treatment.

Patients with rheumatoid arthritis (RA) may develop small vessel vasculitis or necrotising arteritis, but it is the latter who have the worse prognosis, ${ }^{2}$ which is improved by aggressive immunosuppression. ${ }^{41}$ Their identification by raised FVIII RAg in comparison with the normal levels found in uncomplicated RA, despite active synovitis, nodules, or small vessel vasculitis, may be clinically useful. FVIII RAg was, however, slightly raised in two patients with RA, complicated by weight loss and a marked acute phase response. It was markedly increased in patients with Felty's syndrome in the apparent absence of vasculitis, to $1665 \%$ in one case. 
FVIII RAg was variably raised in patients with SLE, MCTD, and PM, often, but not always, reflecting clinical disease activity or apparent vasculitis, which may point to pathogenetic differences of the various manifestations of these diseases. We did not find raised FVIII RAg levels in progressive systemic sclerosis (PSS) or primary Raynaud's disease as previously reported, ${ }^{30}$ but the former had clinically inactive disease, apart from one patient with digital ischaemia who had raised FVIII RAg levels.

An increase of FVIII RAg does not only occur with vasculitic damage as we and others have found it slightly, but significantly, raised in PVD $^{26}$ without apparent irreversible ischaemia, and following surgical trauma. It has also been reported to be raised after myocardial infarction. ${ }^{26} 27$

Although FVIII RAg rises rapidly after trauma, and has a short half life of 240-270 minutes, it may remain raised for 30 days after myocardial infarction. ${ }^{27}$ It fell within 30 days in parallel with clinical improvement in a patient with polyarteritis nodosa followed up closely (Fig. 4), but the timing of changes in FVIII RAg in response to treatment needs establishing.

The endothelium is the major source of FVIII $\mathrm{RAg}$, but it is also present in platelets. ${ }^{35}{ }^{36}$ Plateletendothelial interactions or platelet destruction by autoimmune thrombocytopenia in connective tissue diseases or by splenic consumption in Felty's syndrome could be important, and the latter could account for increased levels in the apparent absence of vasculitis. We have no data on platelet turnover in these patients.

The increase of FVIII RAg is not simply part of an acute phase response as, although raised after trauma, it was not increased in active articular rheumatoid arthritis accompanied by a raised $\mathrm{C}$ reactive protein, and it did not correlate with $\mathrm{C}$ reactive protein in systemic necrotising arteritis.

At present, no specific marker of disease activity in systemic necrotising arteritis is available,${ }^{6}$ though immune complexes are sometimes detected. ${ }^{2} \mathrm{C}$ reactive protein levels may be useful in monitoring disease activity, ${ }^{42}$ but these are non-specific, rising in infection, and do not show a normal response in SLE $^{43}$ or PSS. ${ }^{44}$ We found CRP to be a poor indicator of clinical disease activity in our patients (Figs 3 and 4).

In conclusion, FVIII RAg was raised in systemic necrotising arteritis and large vessel arteritis, but not in small vessel vasculitis. It may therefore prove a useful non-invasive investigation to determine the extent of vasculitis with its therapeutic and prognostic implications. Whether this difference relates to qualitative or quantitative differences in endothelial cells or platelet turnover is unclear. FVIII RAgू. levels reflected changes in clinical activity and may: be of value in monitoring the response to potentially toxic treatment. Changes in FVIII RAg, howevero are not specific to vasculitis as other causes of vascular damage can produce raised concentrations $\frac{\overline{\bar{c}}}{\bar{s}}$ It is not simply a secondary effect, an acute phas response, but is probably directly reflecting the pathological process in the vessel. To establish fully whether it has a role as a routine investigatio $P$ procedure requires further experience, but it $\vec{s}$ measurement is simple and appears to offer more than is currently available in the assessment o. vasculitis, either occurring de novo or as a feature of connective tissue disease.

We wish to thank the staff of the Department of Haematology Bristol Royal Infirmary, for their technical assistance; and Dr G b Scott, Dr J Whicher, Professor P A Bacon. Dr D Adu, and Mr M Horrocks for their cooperation. We with to thank the Arthritis and Rheumatism Council for Research for their support.

\section{References}

1 Fauci A S, Haynes B F, Katz P. The spectrum of vasculitis clinical, pathologic, immunologic and therapeutic considerations. Ann Intern Med 1978; 89: 660-76.

2 Scott D G I, Bacon P A, Tribe C R. Systemic rheumatoi vasculitis: a clinical and laboratory study of 50 cases. Medicin (Baltimore) 1981; 60: 288-97.

3 Pinching A J, Lockwood C M, Pussell B A, et al. Wegener granulomatosis: observations on 18 patients with severe renag disease. $Q J$ Med 1983; 52: 435-60.

4 Scott D G I, Bacon P A. Elliot P J. Tribe C R, Wallington T B $\overrightarrow{\bar{\sigma}}$ Systemic vasculitis in a district general hospital 1972-1980B clinical and laboratory features, classification and prognosis 80 cases. $Q J$ Med 1982; 51: 292-311.

5 Cohen R D. Conn D L. Ilstrup D M. Clinical features: prognosis and response to treatment in polyarteritis. Mayo Cliq Proc 1980; 55: 146-55.

6 Anonymous. Systemic vasculitis [Editorial]. Lancet 1985: 1252-4.

7 Brinkhous K M, Sultzer D L, Reddick R L, Griggs T R் Elevated plasma von Willebrand factor levels as an index of acute endothelial injury: use of a hypotonic injury model in rats [Abstract]. Fed Proc 1980; 39: 630.

8 Pcake I R. The nature of factor VIII. Clin Sci 1984; 67: 561-7

9 Sodetz J M, Pizzo S V. McKec P. Relationship of sialic acid tQ function and in vivo survival of human factor VIII/voñ Willebrand factor protein. J Biol Chem 1977; 252: 5538-46

10 Over J, Sixma J J, Trieschnigg A M C, et al. Survival of radiolabelled human factor VIII in vivo. Thromb Haemo is 1977; 38: 51 .

11 Bloom A L. Giddings J C, Wilks C J. Factor VIII on the vascular intima: possible importance in hacmostasis and throm bosis. Nature New Biol 1973; 241: 217-9.

12 Hoyer L W, De Los Santos R P. Hoyer J R. Antihemophil factor antigen: localisation in endothelial cells by immuno fluorescent microscopy. J Clin Invest 1973; 52: 2737-44.

13 Rand J H, Gordon R E, Sussman I I, Chu S V. Solomon V Electron microscopic localisation of factor VIII-related antige? in human blood vessels [Abstract]. Circulation 1980; 62: II 169.

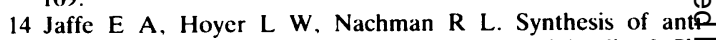
hemophilic factor antigen by cultured endothelial cells. $J C l$ Invest 1973; 52: 2757-64. 
15 Tuddenham E G D, Lazarchick J, Hoyer L W. Synthesis and release of factor VIII by cultured human endothelial cells. $\mathrm{Br} \mathrm{J}$ Haematol 1981; 47: 617-26.

16 Chan V. Chan T K. Cell free translation of factor VIII related protein [Abstract]. Thromb Haemost 1983; 50: 18.

17 Holmberg L, Nilsson I M. AHF related protein in clinical praxis. Scand J Haematol 1974; 12: 221-31.

18 Ekberg M, Nilsson I M. Factor VIII and glomerulonephritis. Lancet 1975; i: 1111-3.

19 Ekberg M R, Nilsson I M, Linell F. Significance of increased factor VIII in early glomerulonephritis. Ann Intern Med 1976; 83: $337-41$.

20 Remuzzi G, Livio M, Roncaglioni M C, Mecca G, Donati M B, de Gaetano G. Bleeding in renal failure: Is von Willebrand factor implicated? $\mathrm{Br}$ Med $J$ 1977; ii: 359-61.

21 Ambruso D R, Durante D P, McIntosh R M. Hathaway W E. Factor VIII and renal disease. Ann Intern Med 1977; 87: 636.

22 Warrell R P Jr. Hultin M B, Coller B S. Increased factor VIII/von Willebrand factor antigen and von Willebrand factor activity in renal failure. Am J Med 1979; 66: 226-8.

23 Lufkin E, Fass D, O'Fallow D, Bowie E. Increased von Willebrand's factor in diabetes mellitus. Metabolism 1979; 28: 63-6.

24 Munteau W E, Borkenstein M H, Haas J. Elevation of factor VIII coagulant activity over factor VIII coagulant antigen in diabetic children without vascular disease: a sign of activation of the factor VIII coagulant moiety during poor diabetes control. Diabetes 1985; 34: 140-4.

25 Coller B S, Frank R N, Milton R D, Gralnick R. Plasma co-factors of platelet function: correlation with diabetic retinopathy and haemoglobins $A$. Studies in diabetic patients and normal persons. Ann Intern Med 1978; 88: 311-6.

26 Cucuianu M P. Missits I, Olinic N, Roman S. Increased ristocetin-cofactor in acute myocardial infarction: a component of the acute phase reaction. Thromb Haemost 1980; 43: 41-4.

27 Giustolisi R, Musso R, Cacciola E, Cacciola R R, Russo M, Petralito A. Abnormal plasma levels of factor VIII/von Willebrand factor complex in myocardial infarction-expression of acute phase reaction or index of vascular endothelium damage? Thromb Haemost 1984; 51: 408.

28 Carvalho A C A, Bellman S, Saullo V J, Quinn D, Zapol W M. Altered factor VIII in acute respiratory failure. $N$ Engl J Med 1982; 307: 1113-9.

29 Federici A B, Fox R I, Espinoza L R, Zimmerman T S. Elevation of von Willebrand factor is independent of erythrocyte sedimentation rate and persists after glucocorticoid treatment in giant cell arteritis. Arthritis Rheum 1984; 27: 1046-9.
30 Kahaleh M B, Osborn I, Le Roy E C. Increased factor VIII/von Willebrand factor antigen and von Willebrand factor activity in scleroderma and in Raynaud's phenomenon. Ann Intern Med $1981 ; 94: 482-4$.

31 Nusinow S R, Federici A B, Zimmerman T S, Curd J G. Increased von Willebrand factor antigen in the plasma of patients with vasculitis. Arthritis Rheum 1984: 27: 1405-10.

32 Ropes M W, Bennett G A, Cobb S. Jacox R, Jessar R A. Revision of diagnostic criteria for rheumatoid arthritis. Bull Rheum Dis 1958; 9: 175-6.

33 Mancini G. Carbonara A O. Hermans J F. Immunochemical quantification of antigens by single radial immunodiffusion. Immunochemistry 1965; 2: 235-54.

34 Cejka J. Enzyme immunoassay for factor VIII-related antigen. Clin Chem 1982; 28: 1356-8.

35 Meucci P, Peak I R, Bloom A L. Factor VIII related activities in normal. haemophilic and von Willebrand's disease platelet fractions. Thromb Haemost 1978; 40: 288-301.

36 Giddings J C. Brookes L R. Piovella F, Bloom A L. Immunohistological comparison of platelet factor 4, (PF4), fibronectin (Fn) and factor VIII related antigens (VIII RAg) in human platelet granules. $\mathrm{Br} J$ Haematol 1982; 52: 79-88.

37 Nachman R. Levine R. Jaffe E A. Synthesis of factor VIII antigen by cultured guinea pig megakaryocytes. J Clin Invest 1977; 60: 914-21.

38 Stel H V, Sakariassen K S, de Groot P G, Van Mourik J A, Sixma J J. Von Willebrand factor in the vessel wall mediates platelet adherence. Blood 1985; 65: 85-90.

39 Richardson J E, Grady M, Glynn M, Keystone E C. Factor VIII antigen in Takayasu's arteritis [Abstract]. Arthritis Rheum 1985; 28: S16.

40 Nusinow S R, Zimmerman T S, Curd J G. The value of von Willebrand's factor related antigen in dermal vasculitis [Abstract]. Arthritis Rheum 1985; 28: S97.

41 Scott D G I, Bacon P A. Intravenous cyclophosphamide and methylprednisolone in treatment of systemic rheumatoid vasculitis. Am J Med 1984; 76: 377-84.

42 Hind C R K, Savage C O, Winearls C G, Pepys M B. Objective monitoring of disease activity in polyarteritis by measurement of serum C reactive protein concentration. $\mathrm{Br}$ Med J 1984; 288: 1027-30.

43 Becker G J, Waldburger M, Hughes G R V, Pepys M B. Value of serum C-reactive protein measurement in the investigation of fever in systemic lupus erythematosus. Ann Rheum Dis 1980; 39: 50-2.

44 Whicher J T, Martin M F R, Dieppe P A. Absence of prostaglandin stimulated increase in acute phase proteins in systemic sclerosis. Lancet 1980; ii: 1187-8. 